\title{
EKSTRAK DAUN SUKUN SEBAGAI INHIBITOR ALAMI PENGHAMBAT KOROSI PADA KAWAT STAINLESS STEEL
}

\author{
Mirna Febriani*, Imam Fachrudin** \\ *Departemen Ilmu Material dan Teknologi kedokteran Gigi, Fakultas Kedokteran Gigi, \\ Universitas Prof.Dr.Moestopo(Beragama), Jakarta \\ **Fakultas Kedokteran Gigi, Universitas Prof.Dr.Moestopo(Beragama), Jakarta \\ Korespondensi: Mirna Febriani, mirnarifky@yahoo.com
}

\begin{abstract}
ABSTRAK
Latar belakang: pemakaian kawat stainless steel pada bidang kedokteran gigi cukup banyak digunakan, terutama untuk perawatan di bidang ortodonsi dan prostodonsi yang menggunakan kawat stainless steel. Rongga mulut merupakan lingkungan yang sangat ideal untuk terjadinya korosi, yang dapat disebabkan oleh saliva. Pencegahan korosi pada kawat stainless steel dapat dilakukan dengan memakai inhibitor korosi yang bersifat organik maupun non organik.Salah satu inhibitor organik yang dapat digunakan untuk mencegah korosi adalah daun sukun. Tujuan: tujuan dari penelitian ini adalah untuk mengetahui efektivitas ekstrak daun sukun dalam menghambat laju korosi kawat stainless steel. Metode: metode yang digunakan untuk penelitian ini menggunakan alat uji Atomic Absorption Spectrophometric. Hasil: hasil penelitian menunjukkan adanya perbedaan pelepasan ion kromium pada perendaman dalam saliva dan ekstrak daun sukun pada hari ke 1, 3, 7 dan 14. Perhitungan statistik dengan Independent T-test 0,000 dengan $\mathrm{p}<0,05$ menunjukkan hasil perbedaan yang bermakna. Kesimpulan: kesimpulan dari penelitian ini menunjukkan bahwa ekstrak daun sukun dapat menghambat laju korosi kawat stainless steel.
\end{abstract}

Kata kunci: Ion Kromium, stainless steel, saliva, daun sukun

\section{ABSTRACT}

Background: the use of stainless steel wires in the field of dentistry is widely used, especially for orthodontic and prosthodontic treatment using stainless steel wire. The oral cavity is the ideal environment for corrosion, which can be caused by saliva. Prevention of corrosion on stainless steel wires can be done by using corrosion inhibitor that organic or non organic. One of the organic inhibitors that can be used to prevent corrosion is the leaves of breadfruit. Purpose: the purpose of this study was to determine the effectiveness of breadfruit leaf extract in inhibiting the corrosion rate of stainless steel wire. Method: the method used for this research using Atomic Absorption Spectrophometric test. Result: the results showed that the difference of chromium ion releases on soaking in saliva and breadfruit leaf extracts on days 1, 3, 7 and 14. Statically calculation 0,000 with independent T-test with $p<0,05$ showed significant difference. Conclusion: the conclusion of this study shows that breadfruit leaf extract can inhibit the corrosion rate of stainless steel wires.

Keywords: Chromium ion, stainless steel, saliva, breadfruit leaf

\section{LATAR BELAKANG}

Pemakaian alat ortodonsi cekat dalam perawatan ortodonsi merupakan perawatan yang sangat banyak diminati oleh masyarakat dimulai dari orang dewasa, remaja dan anak-anak. Selain sebagai bagian dari gaya hidup, penggunaan alat ortodonsi cekat memiliki kemampuan dalam mengembalikan fungsi kunyah yang optimal dan sangat berpengaruh terhadap tampilan estetik seseorang. Hal ini disebabkan karena dalam pemakaiannya, alat ini mampu memberikan senyum yang menarik sehingga meningkatkan kepercayaan diri bagi pemakainya. ${ }^{1,2}$

Korosi pada alat ortodonsi merupakan suatu bentuk permasalahan yang bersifat konstan dan sulit untuk dihilangkan, namun dapat dicegah. Pencegahan pada korosi kawat ortodonsi ini dapat dilakukan dengan melibatkan inhibitor korosi baik yang bersifat organik maupun non-organik. Akan tetapi, inhibitor non-organik merupakan jenis bahan kimia yang mahal, berbahaya, dan tidak ramah lingkungan yang dapat 
memberikan efek buruk bila berinteraksi langsung dengan tubuh manusia. saat ini sedang dikembangkan penggunaan bahan organik yang lebih alami untuk dijadikan sebagai bahan inhibitor korosi yang lebih aman dan biokompatibel dengan tubuh. , $^{3,5}$

Korosi merupakan kerusakan yang terjadi pada suatu material akibat reaksi dengan lingkungan sekitarnya. Proses korosi melibatkan 2 reaksi simultan yakni oksidasi dan reduksi (redoks). Ketika spesimen logam murni (disebut elektroda) ditempatkan pada medium cairan (disebut elektrolit) yang tidak mengandung ion-ion specimen, maka ion logam akan cenderung larut ke dalam medium dan permukaan logam yang hilang ionnya akan memulai proses redeposisi untuk mempertahankan sifat logam tersebut, transfer ion logam ke medium cairan disebut proses oksidasi (hilangnya elektron) dan redeposisi yang menyebabkan reduksi. ${ }^{6}$

Korosi dimulai dari terjadinya tarnish pada logam, kemudian berlanjut dengan lepasnya ion-ion logam, akhirnya terjadilah korosi. Tarnish adalah berkurangnya pewarnaan permukaan logam atau perubahan pada permukaan logamyang telah dipoles. Penyebab tarnish adalah: (1) Air, oksigen dan ion klor yang terdapat di saliva.(2) Deposit-deposit dalam mulut yang menempel pada permukaan logam.(3) Stain yang disebabkan oleh bakteri. (4) Pembentukan senyawa-senyawa tertentu seperti oksida, sulfida atau klor. ${ }^{7,8}$

Kromium merupakan komponen tambahan yang berfungsi meningkatkan ketahanan terhadap korosi. Kromium padapermukaan logam bereaksi dengan oksigen membentuk kromium oksida yang tahanterhadap korosi. Nikel berfungsi membantu ketahanan logam terhadap korosi sertamemperkuat logam. ${ }^{9,10,11}$ Akan tetapi kelemahan dari unsur Ni dan $\mathrm{Cr}$ adalah dapat menyebabkan alergi apabila terlepas dalam rongga mulut. ${ }^{12}$

Inhibitor korosi adalah salah satu cara yang dapat dilakukan untuk mencegah terjadinya korosi adalah dengan penggunaan inhibitor korosi adalah suatu zat kimia yang bila ditambahkan kedalam suatu lingkungan, dapat menurunkan laju penyerangan korosi lingkungan itu terhadap suatu logam. Mekanisme penghambatannya terkadang lebih dari satu jenis. Sejumlah inhibitor menghambat korosi melalui cara adsorpsi untuk membentuk suatu lapisan tipis yang tidak nampak dengan ketebalan beberapa molekul saja, ada pula yang karena pengaruh lingkungan. ${ }^{13,14,15}$

Inhibitor korosi terdiri dari inhibitor anorganik dan organik (green inhibitor). Inhibitor anorganik antara lain arsenat, kromat, silikat, dan fosfat yang merupakan jenis bahan kimia yang mahal, berbahaya, dan tidak ramah lingkungan, sehingga akan memberi efek buruk bila berinteraksi langsung dengan tubuh manusia. Oleh karena itu saat ini sedang dikembangkan penggunaan bahan organik yang lebih alami untuk dijadikan bahan inhibitor korosi yang lebih aman dan biokompatibel dengan tubuh. ${ }^{11,12}$

Salah satu inhibitor alami yang banyak digunakan adalah daun sukun (Artocarpus altilis) mengandung senyawa saponin, polifenol, tanin, asam hidrosianat, kalium, aseticolin, riboflavin, dan phenol. Daun sukun mengandung senyawa flavonoid yaitu 8-geranyl- 4,57- trihydroxyflavone yang bersifat sebagai antidiabetes kuat. Sementara itu, senyawa flavonoid geranyl daun sukun bermanfaat sebagai antikanker. Kandungan flavonoid juga terbukti sebagai antiinflamasi, antiaterosklerosis, dan platelet. Daun sukun juga terbukti secara ilmiah melindungi jantung. ${ }^{16,17}$

\section{METODE PENELITIAN}

Penelitian ini dilakukan secara eksperimental laboratorik, dengan jumlah sampel 8 sampel perkelompok perlakuan, penelitian dilakukan selama bulan Juni-juli 2017, lokasi penelitian di laboratorium pengujian Balai Pengkajian Bioteknologi, Badan Pengkajian dan Penerapan Teknologi, Puspitek Serpong Tangerang Selatan. Data di analisis memakai uji t-independent.

\section{Alat dan Bahan}

1. Tabung

2. Gelas Ukur

3. Tang pemotong kawat

4. AAS (Atomic Absorption Spectrophotometric)

5. Kawat stainless steel

6. Saliva buatan

7. Ekstrak daun sukun yang dari Laboratorium Tekhnologi Industri IPB Bogor

Kawat stainless steel yang digunakan dengan diameter $0.4 \mathrm{~mm}$ yang kemudian dipreparasi dengan panjang $40 \mathrm{~mm}$ sehingga dihasilkan 8 sampel kawat dengan panjang yang sama. Kemudian dibagi menjadi 8 kelompok (4 kelompok kontrol dan 4 kelompok perlakuan) yang masing-masing terdiri dari 1 buah. Lakukan perendaman kawat stainless steel ke dalam larutan saliva buatan $\mathrm{pH} 6,75 \pm 0,15$ dan ekstra daun sukun sebanyak $5 \mathrm{ml}$ pada tabung borosilicate glass yang kemudian ditutup rapat, serta dilakukan penyimpanan pada suhu ruangan selama 1, 3, 7, dan 14 hari waktu perendaman. Selanjutnya lakukan pengukuran pelepasan ion $\mathrm{Cr}$ pada masingmasing perendaman dengan menggunakan AAS (Atomic Absorption Spectrophotometric), tiap sampel baik kelompok kontrol dan kelompok perlakuan dilakukan pengukuran pelepasan ion $\mathrm{Cr}$ dengan 3 kali pengukuran meliputi sampel basah (1), sampel setengah kering(2) dan sampel kering (3), lalu diambil nilai rata-ratanya. 


\section{HASIL PENELITIAN}

Berdasarkan hasil penelitian didapatkan hasil sebagai berikut:

Tabel 1. Hasil pengukuran pelepasan ion $\mathrm{Cr}$ yang terjadi pasca perendaman pada ekstrak daun sukun.

\begin{tabular}{ccccccccc}
\hline No. & $\begin{array}{c}\text { Kode } \\
\text { sampel }\end{array}$ & Bentuk & Parameter & & Hasil & & Rerata \\
\hline & & & & & $\mathbf{1}$ & $\mathbf{2}$ & $\mathbf{3}$ & \\
1 & 1 hari & Cair & Cr & Ppm & 4,964 & 4,967 & 4,811 & 4,914 \\
2 & 3 hari & Cair & Cr & Ppm & 4,696 & 4,657 & 4,664 & 4,673 \\
3 & 7 hari & Cair & Cr & Ppm & 4,446 & 4,213 & 4,067 & 4,235 \\
4 & 14 hari & Cair & Cr & Ppm & 3,046 & 2,496 & 1,877 & 2,473 \\
\hline
\end{tabular}

Tabel 1. menunjukkan hasil pengukuran uji laboratorium jumlah pelepasan ion $\mathrm{Cr}$ pada kelompok perlakuan ekstrak daun sukun dengan perendaman kawat ortodontik stainless steel dalam interval waktu yang berbeda-beda pada suhu $37^{\circ}$. Pelepasan ion $\mathrm{Cr}$ bervariasi untuk masing-masing sampel. Dapat terlihat bahwa hasil perendaman 1, 3, 7 dan 14 hari terjadi penurunan pelepasan ion $\mathrm{Cr}$ pada masing-masing larutan yaitu pada kelompok perlakuan ekstrak daun sukun perendaman 1 hari terjadi pelepasan ion $\mathrm{Cr}$ sebesar 4,914 ppm, pada perendaman 3 hari sebesar 4,673 ppm, pada perendaman 7 hari sebesar 4,235 ppm, dan pada perendaman 14 sebesar $2,473 \mathrm{ppm}$.

Tabel 2. Hasil pengukuran pelepasan ion $\mathrm{Cr}$ yang terjadi pasca perendaman pada saliva buatan.

\begin{tabular}{cccccccccc}
\hline \multirow{2}{*}{ No } & $\begin{array}{c}\text { Kode } \\
\text { Sampel }\end{array}$ & Bentuk & Parameter & Satuan & & Hasil & \multicolumn{2}{c}{ Rerata } \\
\cline { 5 - 8 } & & & & & $\mathbf{1}$ & $\mathbf{2}$ & $\mathbf{3}$ & \\
\hline 1 & 1 hari & Cair & Cr & Ppm & 0,079 & 0,082 & 0,075 & 0,075 \\
2 & 3 hari & Cair & Cr & Ppm & 0,073 & 0,068 & 0,070 & 0,070 \\
3 & 7 hari & Cair & Cr & Ppm & 0,082 & 0,072 & 0,070 & 0,075 \\
4 & 14 hari & Cair & Cr & Ppm & 0,063 & 0,073 & 0,056 & 0,065 \\
\hline
\end{tabular}

Tabel 2. menunjukkan hasil pengukuran uji laboratorium jumlah pelepasan ion $\mathrm{Cr}$ pada kelompok kontrol saliva buatan dengan perendaman kawat ortodontik stainless steel dalam interval waktu yang berbeda-beda pada suhu $37^{\circ}$.

Pelepasan ion $\mathrm{Cr}$ bervariasi untuk masingmasing sampel. Hasil menunjukkan bahwa perendaman 1, dan 3 hari terjadi penurunan pelepasan ion $\mathrm{Cr}$ pada masing- masing larutan yaitu pada kelompok kontrol saliva buatan perendaman 1 hari terjadi pelepasan ion $\mathrm{Cr}$ sebesar 0,075 pada perendaman 3 hari sebesar 0,070 ppm, sedangkan pada perendaman 7 hari mengalami peningkatan sebesar 0,075 ppm, namun pada perendaman 14 hari terjadi peneurunan sebesar $0,065 \mathrm{ppm}$.

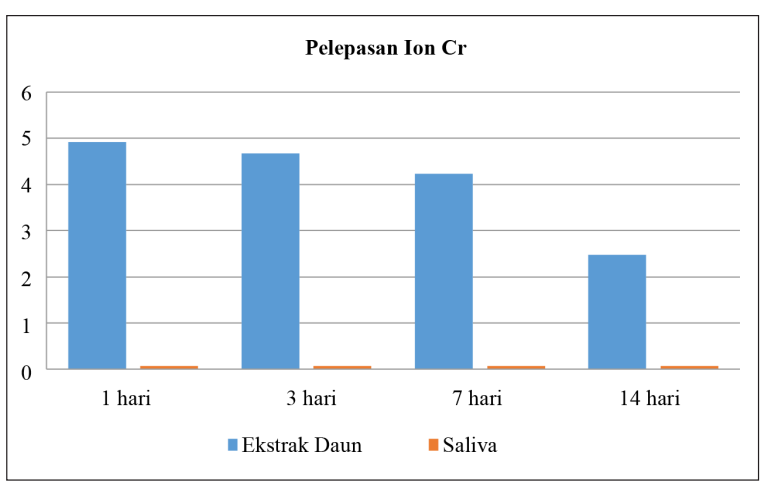

Grafik 1. Pelepasan ion $\mathrm{Cr}$

Grafik 1. menunjukkan adanya perbandingan pelepasan ion $\mathrm{Cr}$ yang signifikan antara perendaman selama 1, 3, 7 dan 14 hari pada ekstrak daun sukun dan perendaman selama 1, 3, 7 dan 14 hari pada saliva buatan.

Berdasarkan hasil penelitian dilakukan analisa data dengan menggunakan program statistik berbasis komputer dan didapatkan hasil sebagai berikut:

Tabel 3. Independent samples Test perbandingan perendaman 1 hari.

\begin{tabular}{|c|c|c|c|c|c|c|c|c|c|}
\hline \multicolumn{5}{|c|}{$\begin{array}{l}\text { Levene's Test } \\
\text { for Equality of Variances }\end{array}$} & \multicolumn{5}{|c|}{ t-test for Equality of Means } \\
\hline & & \multirow[b]{2}{*}{$\mathrm{F}$} & \multirow[b]{2}{*}{ Sig. } & \multirow[b]{2}{*}{$\mathrm{T}$} & \multirow[b]{2}{*}{ Df } & \multirow[b]{2}{*}{$\begin{array}{l}\text { Sig. (2- } \\
\text { tailed) }\end{array}$} & \multirow{2}{*}{$\begin{array}{l}\text { Mean } \\
\text { Differ } \\
\text { ence }\end{array}$} & \multicolumn{2}{|c|}{$\begin{array}{c}95 \% \\
\text { Confidence } \\
\text { Interval } \\
\text { Difference }\end{array}$} \\
\hline & & & & & & & & Lower & Uper \\
\hline & Equal & & & & & & & & \\
\hline & variances & & & & & & 4,835 & 4,692 & 4,97 \\
\hline \multirow[t]{4}{*}{ hasil } & assumed & 14,81 & ,018 & 93,516 & 4 & 0,000 & 67 & 1 & 924 \\
\hline & $\begin{array}{l}\text { Equal } \\
\text { variances }\end{array}$ & & & & & & & & \\
\hline & not & & & & & & 4,835 & 4,613 & 5,05 \\
\hline & assumed & & & 93,516 & 2,006 & 0,000 & 67 & 83 & 75 \\
\hline
\end{tabular}

Tabel 3. menunjukkan hasil uji t-ndependent untuk perendaman selama 1 hari pada kelompok saliva buatan dan kelompok ekstrak daun sukun. Uji $t$-ndependent dilakukan setelah diketahui data terdistribusi normal. Didapatkan hasil kelompok dengan tingkat kemaknaan $0,00 \quad(\mathrm{p}<0,05)$ yang artinya terdapat perbedaan bermakna terhadap pelepasan ion $\mathrm{Cr}$ antara yang direndam 1 hari dalam saliva buatan dan yang direndam 1 hari dalam ekstrak daun sukun. 
Tabel 4. Uji t-ndependent perbandingan perendaman 3 hari.

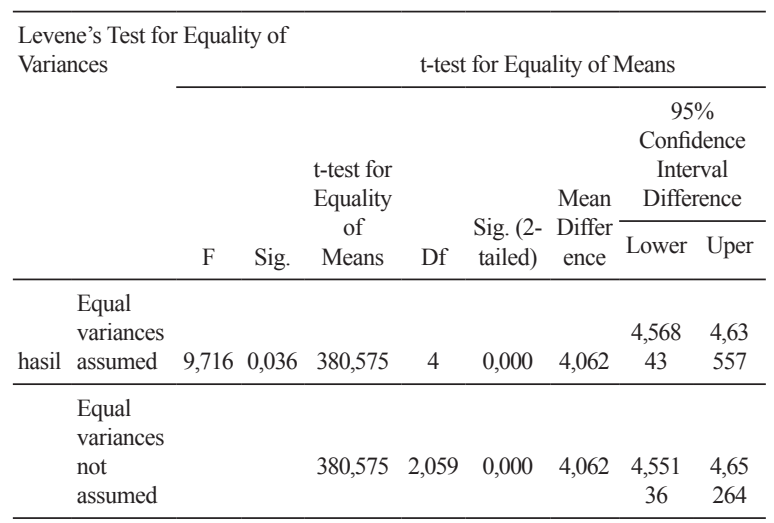

Tabel 4 menunjukkan hasil uji t-ndependent untuk perendaman selama 3 hari pada kelompok saliva buatan dan kelompok ekstrak daun sukun. Didapatkan hasil kelompok dengan tingkat kemaknaan 0,00 $(p<0,05)$ yang artinya terdapat perbedaan bermakna terhadap pelepasan ion $\mathrm{Cr}$ antara yang direndam 3 hari dalam saliva buatan dan yang direndam 3 hari dalam ekstrak daun sukun.

Tabel 5. Uji t-ndependent perbandingan perendaman 7 hari.

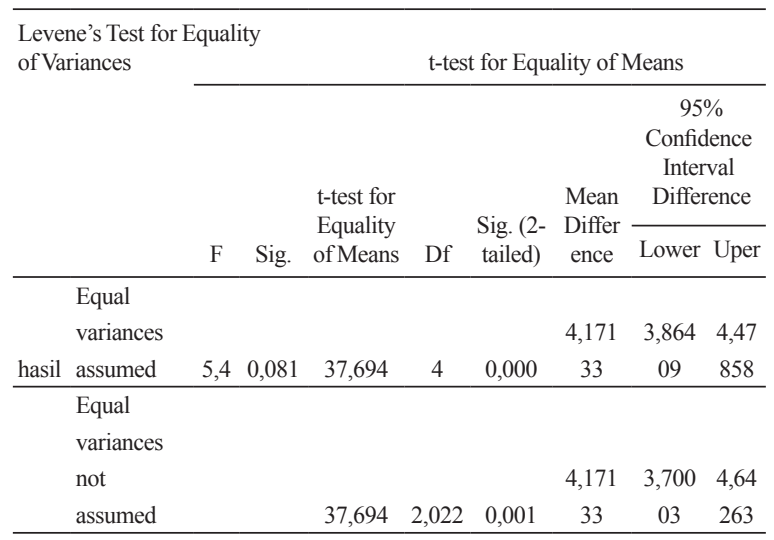

Tabel 5. menunjukkan hasil uji t-ndependent untuk perendaman selama 7 hari pada kelompok saliva buatan dan kelompok ekstrak daun sukun. Didapatkan hasil kelompok dengan tingkat kemaknaan 0,00 dan $0,001 \quad(p<0,05)$ yang artinya terdapat perbedaan bermakna terhadap pelepasan ion $\mathrm{Cr}$ antara yang direndam 7 hari dalam saliva buatan dan yang direndam 7 hari dalam ekstrak daun sukun.

Tabel 6. menunjukkan hasil uji Uji t-ndependent untuk perendaman selama 14 hari pada kelompok saliva buatan dan kelompok ekstrak daun sukun. Didapatkan hasil kelompok dengan tingkat kemaknaan 0,002 dan $0,0019(\mathrm{p}<0,05)$ yang artinya terdapat perbedaan bermakna terhadap pelepasan ion $\mathrm{Cr}$ antara yang direndam 14 hari dalam saliva buatan dan yang direndam 14 hari dalam ekstrak daun sukun.
Tabel 6. Uji t-ndependent perbandingan perendaman 14 hari.

\begin{tabular}{|c|c|c|c|c|c|c|c|c|}
\hline \multirow[t]{2}{*}{$\begin{array}{l}\text { Levene's Test for } \\
\text { Variances }\end{array}$} & r Equal & ity of & \multicolumn{6}{|c|}{ t-test for Equality of Means } \\
\hline & $\mathrm{F}$ & Sig. & $\begin{array}{l}\text { t-test for } \\
\text { Equality } \\
\text { of Means }\end{array}$ & Df & $\begin{array}{l}\text { Sig. (2- } \\
\text { tailed) }\end{array}$ & $\begin{array}{c}\text { Mean } \\
\text { Differ } \\
\text { ence }\end{array}$ & $\begin{array}{r}1.9 \\
\text { Confi } \\
\text { Inte } \\
\text { Diffe } \\
\text { Lower }\end{array}$ & $\begin{array}{l}5 \% \\
\text { dence } \\
\text { val } \\
\text { ence } \\
\text { Uper }\end{array}$ \\
\hline $\begin{array}{c}\text { Equal } \\
\text { variances } \\
\text { hasil } \\
\text { assumed }\end{array}$ & 4,365 & 105 & 7,134 & 4 & 0,002 & 2,409 & $\begin{array}{c}1,471 \\
41\end{array}$ & $\begin{array}{l}3,34 \\
659\end{array}$ \\
\hline $\begin{array}{l}\text { Equal } \\
\text { variances } \\
\text { not } \\
\text { assumed }\end{array}$ & & & 7,134 & 2,001 & 0,019 & 2,409 & $\begin{array}{c}0,956 \\
62\end{array}$ & $\begin{array}{c}3,86 \\
138\end{array}$ \\
\hline
\end{tabular}

\section{PEMBAHASAN}

Perawatan ortodonsi merupakan salah satu jenis perawatan dalam bidang kedokteran gigi yang dianggap memiliki peranan penting dalam perbaikan fungsi kunyah dan estetik bagi masyarakat luas. Akan tetapi, perawatan ortodonsi merupakan jenis perawatan yang membutuhkan waktu yang relatif lama.,

Pada umumnya lingkungan yang ada di dalam rongga mulut merupakan lingkungan yang sangat ideal untuk terjadinya biodegradasi logam pada kawat yang dapat memfasilitasi terjadinya proses korosi pada alat ortodonsi $i^{3,4} \mathrm{Cr}$ berfungsi meningkatkan ketahanan terhadap korosi. Kromium pada permukaan logam bereaksi dengan oksigen membentuk kromium oksida yang tahan terhadap korosi., ${ }^{5,}$ Proses korosi selalu diikuti oleh pelepasan ion dari unsur logam. Kandungan dari kawat ortodontik stainless steel yang dapat terlepas yaitu ferum, nikel, dan kromium, namun nikel dan $\mathrm{Cr}$ mendapat perhatian yang lebih banyak oleh karena dapat berdampak buruk jika masuk dalam tubuh, yaitu dapat menyebabkan reaksi alergi, pemicu kanker dan bersifat toksik. ${ }^{7,8}$

Korosi dapat dikurangi dengan bebagai macam cara, cara yang paling mudah dan paling murah adalah dengan menambahkan inhibitor ke dalam media. Inhibitor korosi merupakan suatu zat kimia yang ditambahkan kedalam suatu lingkungan untuk mampu menurunkan laju korosi lingkungan terhadap suatu logam. ${ }^{16,17}$ Suatu inhibitor korosi memiliki kemampuan untuk menghasilkan suatu lapisan pelindung tipis yang nantinya akan melekat pada permukaan logam, sehingga akan mencegah terjadinya kontak langsung dengan lingkungan korosif. ${ }^{9}$

Inhibitor dari ekstrak bahan alam merupakan jenis inhibitor organik yang memiliki sifat yang biodegradabel, aman, mudah didapatkan, biaya murah, dan ramah lingkungan. Ekstrak bahan alam khususnya senyawa yang mengandung atom $\mathrm{N}, \mathrm{O}, \mathrm{P}$, $\mathrm{S}$, dan atom-atom yang memiliki pasangan elektron bebas akan berfungsi sebagai ligan yang membentuk senyawa kompleks dengan logam. ${ }^{10}$ 
Pada umumnya, inhibitor korosi bekerja dengan mekanisme adsorbsi dari molekul dan ion pada logam. Mekanisme absorbsi inhibitor korosi organik pada permukaan logam diawali dengan pergeseran molekulmolekul air yang teradsorbsi pada permukaan logam oleh molekul-molekul inhibitor. Hal ini disebabkan, karena tegangan air lebih tinggi dibandingkan dengan tegangan permukaan inhibitor, sehingga mengakibatkan daya tarik permukaan metal terhadap inhibitor pun menjadi lebih tinggi bila dibandingkan dengan air. Selanjutnya, inhibitor tersebut berikatan dengan ion-ion $\mathrm{Fe}^{2+}$ yang terbentuk pada permukaan metal membentuk senyawa kompleks logam inhibitor. Senyawa inilah yang diharapkan mampu menahan dan membatasi interaksi langsung antara logam dengan larutan korosi. ${ }^{11,12}$

Bila konsentrasi inhibitor korosi yang ditambahkan terlalu besar maka akan menyebabkan daya inhibisi dari suatu inhibitor korosi menurun. Hal ini disebabkan karena pada penambahan inhibitor korosi dengan konsentrasi yang terlalu besar akan menyebabkan tertariknya kembali molekul inhibitor di permukaan logam ke dalam lingkungan larutannya. Sehingga menyebabkan melemahnya interaksi logam dan inhibitor yang berakibat terhadap molekul inhibitor pada permukaan logam tergantikan oleh molekul air ataupun ion lain dari lingkungan yang akan menurunkan efek pelindung dari inhibitor korosi. ${ }^{13,14}$

Ekstrak yang berasal dari tumbuhan memiliki kemampuan sebagai inhibitor. Kemampuan untuk menghambat terjadinya proses korosi yang dimiliki oleh ekstrak yang berasal dari tumbuhan diakibatkan di dalam komposisinya terdapat unsur pokok yang bersifat heterosiklik seperti alkaloid dan flavonoid sedangkan unsur seperti tannin, selulosa dan senyawa polisiklik dapat meningkatkan terjadinya pembentukan film diseluruh permukaan logam. ${ }^{15}$

Menurut penelitian Saádah (2010), dalam daun sukun (Artocarpus altilis) banyak terkandung senyawa kimia yang berkhasiat, seperti polifenol, asam hidrosianat, asetilkoin, tanin, riboflavin, fenol, dan flavanoid. ${ }^{17}$ Menurut penelitian Sally (2010), ekstrak daun sukun mengandung senyawa golongan flavanoid, steroid, saponin, dan polifenol. Serta pada skrining fitokimia menunjukkan adanya beberapa senyawa metabolit sekunder yaitu, alkaloid, flavonoid, terpenoid, saponin, fenolik, steroid dan tanin. ${ }^{18}$

Menurut penelitian Gusmawati (2016), ekstrak daun sukun (Artocarpus altilis) diuji sebagai inhibitor korosi baja St. 37 dalam medium asam klorida dengan menggunakan metoda kehilangan berat, polarisasi potensiodinamik dan analisis foto optik. Berdasarkan metoda kehilangan berat dapat diketahui bahwa laju korosi menurun dengan adanya penambahan ekstrak daun sukun. ${ }^{19}$

Dari penelitian yang sudah dilakukan didapatkan bahwa hasil perendaman dari hari pertama, ke 3, ke 7 dan ke 14 terjadi penurunan pelepasan ion $\mathrm{Cr}$ pada masing masing larutan sampel penelitian yaitu ekstrak daun sukun dan saliva buatan. Namun terdapat perbedaan jumlah pelepasan ion $\mathrm{Cr}$ yang signifikan dari masing-masing kelompok saliva buatan dan kelompok ekstrak daun sukun. Didapatkan bahwa pelepasan ion $\mathrm{Cr}$ pada kelompok ekstrak daun sukun lebih besar dibandingkan dengan pelepasan ion $\mathrm{Cr}$ pada kelompok saliva buatan ditinjau dari perendaman selama $1,3,7$, dan 14 hari.

Dengan demikian dapat dikatakan bahwa pada penelitian ini hipotesis ditolak, pelepasan ion $\mathrm{Cr}$ pada kelompok kawat stainless steel yang direndam dalam ekstrak daun sukun selama 1, 3, 7, dan 14 hari lebih besar dibandingkan dengan yang direndam dalam saliva buatan selama 1, 3, 7, dan 14 hari. Pada penelitian ini kemampuan eksrak daun sukun untuk mencegah korosi semakin meningkat setiap harinya karena pada hari ke 1, 3, 7, dan 14 pelepasan ion $\mathrm{Cr}$ semakin menurun. Hal ini kemungkinan disebabkan karena ion Fe pada permukaan logam berikatan dengan gugus tanin.

\section{KESIMPULAN DAN SARAN}

Pelepasan ion Cr dari kawat stainless steel yang direndam dalam saliva ekstrak daun sukun meningkat pada 24 jam namun menurun pada hari ke 3, 7 dan 14 . Penyebab penurunan pelepasan ion $\mathrm{Cr}$ kemungkinan karena adanya gugus tannin yang berikatan dengan ion Fe semakin meningkat. Ekstrak daun sukun efektif dalam menghambat laju korosi kawat ortodontik berbahan stainless steel dalam jangka waktu yang lama, tetapi perlu penelitian lebih lanjut untuk mengetahui reaksi kima yang terjadi antara gugus tanin dan ion $\mathrm{Cr}$.

\section{DAFTAR PUSTAKA}

1. Wasono NP, Assa YA, Anindita PS. Pelepasan ion nikel dan kromium braket stainless steel yang direndam dalam minuman isotonik. Jurnal Ilmiah Farmasi-UNSRAT. 5(1). P.158-163.

2. Castro SM, Ponces MJ, Lopes JD, Vasconcelos M, Pollmann MCF. Orthodontic wires and its corrosiondthe specific case of stainless steel and beta-titanium. Journal of Dental Sciences2015: 10. P. 1-7.

3. Brandao GAM, Simas Rm, Almeida LM, Silva JM, Meneghim MC, Pereira AC, Almeida HA, Brandao AM. Evaluation of ionic degradation and slot corrosion of metallic brackets by action of different dentifrices. Dental Perss J Ortho 2013;15(1). P.86-93.

4. Anindita, P.S., Bonde, M.M., Fatimawali. Uji Pelepanasan Ion Logam Nikel (Ni) dan Kromium (Cr) Kawat Ortodhontik Stainless Steel yang Direndam dalam Air Kelapa. Jurnal Ilmiah Farmasi- UNSRAT 2016; 5(4). P.40-45.

5. L Ani BEA, Basu BBJ. 2012. Green Inhibitors for corrosion protection of metals and alloys: an overview. International Journal of Corrosion. P. 1-15. 
6. Singh G. Textbook of orthodontics. P. 325 - 36. 2007. 2nd ed. New Delhi: Jaypee Brothers Medical Publishers

7. Machfudzah PA, Amin MN, Putri LSD. Efektivitas ekstrak daun belimbing wuluh sebagai bahan inhibitor korosi pada kawat ortodonsi berbahan dasar nikeltitanium. Artikel ilmiah hasil penelitian mahasiswa 2014.

8. Khamatkar A.deal properties of orthodontic wires and their clinical implication - a review. IOSR Journal of Dental and Medical Sciences (IOSR-JDMS). 2015;14(1). P. 47-50.

9. Tjitro S, Anggono J.Pengaruh lingkungan terhadap efisiensi inhibisi asam askorbat (vitamin c) pada laju korosi tembaga. Jurnal Teknik Mesin.1999; P. 100-7.

10. Haryono G, Sugiarto B, Farid H, Tanoto Y. 2011. Ekstrak bahan alam sebagai inhibitor korosi. Prosiding Seminar Nasional Teknik Kimia "Kejuangan”. P. 1-6.

11. Maksum A.Pengaruh penambahan ekstrak sekam beras hitam terhadap penghambatan korosi logam mild steel dalam larutan 1M HCL. [Tesis] 2011;Jakarta. Universitas Indonesia.

12. Yadla SV, Sirdevi V, Lakshmi MVVC, Kumari SPK. A review on corrosion of metals and protection. International Journal of Engineering Science and Advanced Technology (IJESAT) 2012; 2(3). P. 637-644.
13. Chaturvedi TP, Upadhayay. An overview of orthodontic material degradation in oral cavity. Indian Journal of Dental Research.2010; 21(2). P. 1-9.

14. Park H.Y., Shearer T.R. In Vitro Release of Nickel and Chromium from simulated Orthodontic Ap.pliances. Am J Orthod Dentofacial Orthop.1983; P.150.

15. Raja, P. B., \& Sethuraman, M. G.Natural products as corrosion inhibitor for metals in corrosive media. JMaterials Letters 2008; P. 113 - 116.

16. Djuhariningrum T. Kajian teoritis pengaruh unsur matriks terhadap hasil analisis dengan metoda spektroskopi serapan atom (AAS). Prosiding Seminar Geologi Nuklir dan Sumber Daya Tambang. 2004; P. 306.

17. Sa'adah, L. Isolasi dan Identifikasi Senyawa Tanin dari daun belimbing wuluh (Averrhoa bilimbi L.). Skripsi FST UIN Maulana Malik Ibrahim Malang. 2010;P. 1-5.

18. Lestari Sally P.B., Fatimawali, Geraldine Wulan P. Uji Daya Hambat Ekstrak Daun Sukun (Artocarpus altilis) Terhadap Pertumbuhan Bakteri Streptococcus mutans. Jurnal Ilmiah Farmasi-UNSRAT. 2016; 5(4). P.1-8.

19. Gusmawati S. Ekstrak Daun Sukun (Artocarpus altilis) Sebagai Inhibitor Korosi Baja st.37 Dalam Medium Asam Klorida. (Tesis) Padang.2016;Universitas Andalas. 